\title{
Secure Logistic Management System
}

\author{
Christina Sara Kuriakose ${ }^{1}$, Gopika Regi ${ }^{2}$,Jithu Sara Philip ${ }^{3}$, Reshma K S , \\ Jitha C R \\ Department of Electronics and Communication Engineering HKCET, Pampakuda Ernakulam, India
}

\begin{abstract}
A good logistics management system aim and implements the active forward, and reverse flow and storage of goods, services between the point of source and the point of destination for customer's requirements. This system proposes an idea for solving the complications emerged in the logistics management with the help of advanced technologies like GSM and RFID. The study includes the sections like delivery status of goods, overloading of goods, and the interlocking system. Overloading of goods is analyzed by the help of IR sensors. Accessing of goods by unauthorized person will be informed to the base station and the vehicle will not move. Also the wrong goods accessing from the vehicle will on the buzzer indication and the message will be send to the concerned person via GSM.
\end{abstract}

Keywords: Audrino mega 2560, RFID, GSM, IR sensors, overload detection.

\section{Introduction}

Increase in economic development also increases the competition between the enterprises. It is important to ensure the security of the good to be delivered. Many advanced technologies have to be implemented to provide security. Technology like GSM may be used which helps to ensure the security to the system. In this proposed system RFID, GSM and IR sensors are used. RFID technology is best effective for real time tracking. Authentication should be provided because there is a chance of misplacement of goods. GSM may be used for sending the message when all the goods are delivered. The message can be sent to the authorized person indicating that all the goods are delivered properly.

\section{Existing Systems}

Sharifkhan Pattan1, Sk.La John Basha and L. Srinivas Reddy proposed a system (Design Of A Hybrid wireless Terminal System In Chattel Transportation ) solving problems arising in logistics management using the wireless technologies like RFID, GSM and GPS. RFID is used for the validation of goods and GPS is used for the vehicle tracking. The system also includes the delivery status of goods, current location of vehicle, overloading of goods, interlocking system and check the misplacement of goods. Overloading of goods is identified as the weight of the good will identified from tags [1]. If the goods are misplaced, the system will indicate the authorized person in the base station and the vehicle will not allowed to move. If the wrong goods are taken out from the vehicle the buzzer will be $\mathrm{ON}$ and the message will be intimated to the concerned person via GSM. In another system (The Terminal System Design based on hybrid RFID-GPS in Vehicular communication) designed a vehicle terminal system for continuous monitoring of logistics. The hardware and software design also include RFID, GPS and GSM technologies. In which ultra ARM7 32-bit RISC processor as the central control unit considering both small size and high efficiency [3]. The vehicle can provide the automatic identification of goods that are loaded, the realtime tracking, and remote centralized monitoring. Experimental results suggest that the integration of wireless technologies can built up the accuracy of the system which further improve the efficiency of logistics management. The advanced technologies like GSM and GPS are extensively used for intelligent dispatching. The scope of logistics management has a great change by the arrival of these technologies. Ms. Devyani Mahajan and Dr. K. P. Rane proposed a system(Literature review on WSN based transport management for courier )which aims at reducing the road accidents due to drunken driving. The system immediately locks the engine of the vehicle if it detect the presence of alcohol. At the same time an SMS along with the location of the vehicle is send to three pre-selected contacts [2].

\section{Proposed Methodology}

Proposed system is introduced for providing security for the goods and also ensures the safety and delivery of goods to respective enterprises. It reduces the expenses and enhances the customer service. Also it can avoid the accident rates and will improve the reliability of logistic system. 


\section{Block Diagram}

Figure shows the block diagram of secure logistic management system. Proposed project is having two main sections:

I. Loading of goods and

II. RFID validation.

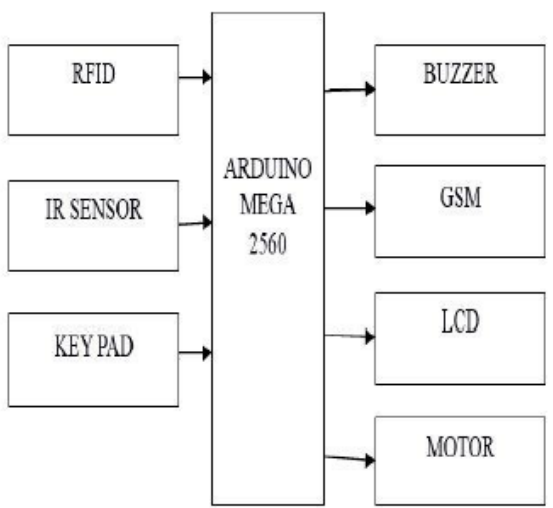

Figure 3.1 Block Diagram

Arduino mega 2560 is the core part of this system. It is a microcontroller board based on the ATmega2560 having 54 pins. The other components are RFID, IR sensors, GSM, keypad, LCD display and buzzer. IR sensors are used to indicate the weight of goods. It is an electronic instrument which is used to sense the objects of its surroundings by emitting infrared radiation. Other main components are RFID reader and tags. RFID technology is similar to the to bar code systems. Reader is producing the radio waves and which will interrogate the passive RFID tags. These tags requires a line-of-sight path to a reader for scanning and also it must be within the range of an RFID reader, it ranges from 3 to 300 feet, in order to read the tag. This technology allows several items to be quickly scanned and provide fast identification of a particular product, even when it is enclosed by several other items. GSM used in this system is SIM 300. It is used to send the SMS to the source using AT commands. LCD in this system is used to displays the information's like company names, loading and unloading details, overload conditions etc. A matrix keypad is interfaced with the arduino IC in order to reduce the number of pins required to read a certain number of digital inputs. Using this key pad, password can be enter to the system. Here a DC motor illustrate the movement of vehicle. L293D driver is used to drive this DC motor. Buzzer is used to alert the authorized person about the invalid user.

\section{Hardware Implementation}

Below figure shows the circuit diagram of logistic management system. Arduino mega 2560 is the brain of this prototype. It is interfaced with IR sensors, RFID, GSM, and Keypad, LCD, DC motors and LED.

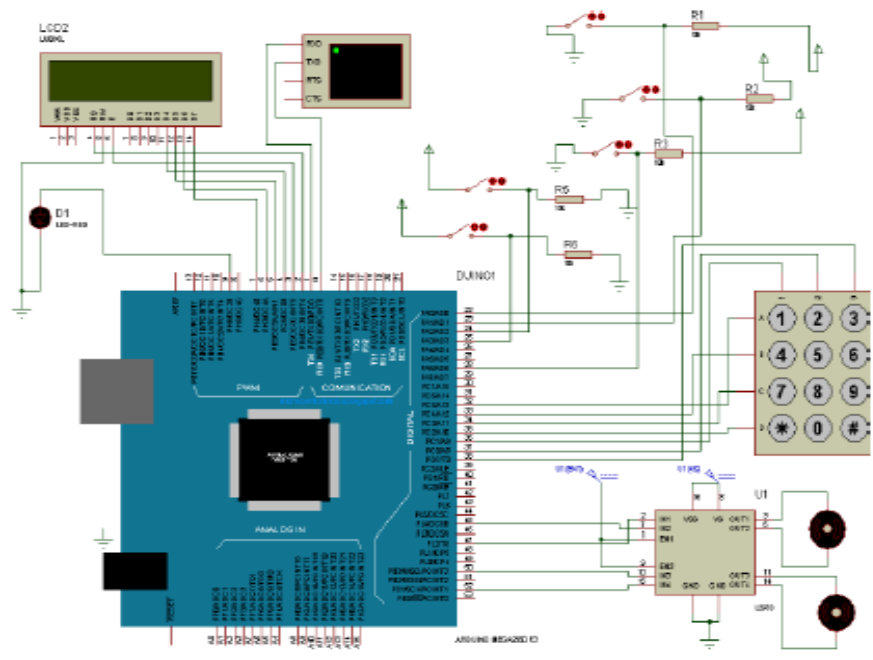

Figure 4.1 Circuit Diagram

Power supply is provided using LM 7805 voltage regulator. Using this IC 5V and 0V can be generated. $12 \mathrm{~V}$ is taken from main supply using an adapter. $12 \mathrm{~V}, 5 \mathrm{~V}$ and $0 \mathrm{~V}$ are taken from 3 pins of LM 7805 . Due to the 
pin limitation of arduino IC, LM 7805 is used to provide supply to all components. Arduino mega is a microcontroller board based on the ATmega328. It has 14 digital input or output pins, 6 analog inputs. It is a good package for a microcontroller and using a USB cable it can be connected to a computer. An RFID reader is used to interrogate RFID tags. Here passive RFID tags are used along with the goods. Virtual Terminal is used to view data coming from Serial Port of IC .GSM 300 is used to send the SMS using the simple AT commands. It follow the RS232 standard and which can be used to interface the modem to micro controllers and computers. LCD in this system is used to displays the information's. It has 16 pins connected to the pins of arduino. DC motor is used for showing demonstration of vehicle movement. LED is connected to indicate the buzzer. For controlling ON and OFF operation of motor two switches are provided to the two pins of the board and IR sensors are indicated by the three resistors R1, R2 and R3 along with switches. For controlling ON and OFF operation of motor two switches are provided to the two pins of the board and IR sensors are indicated by the three resistors R1, R2 and R3 along with switches.

\section{Flowchart}

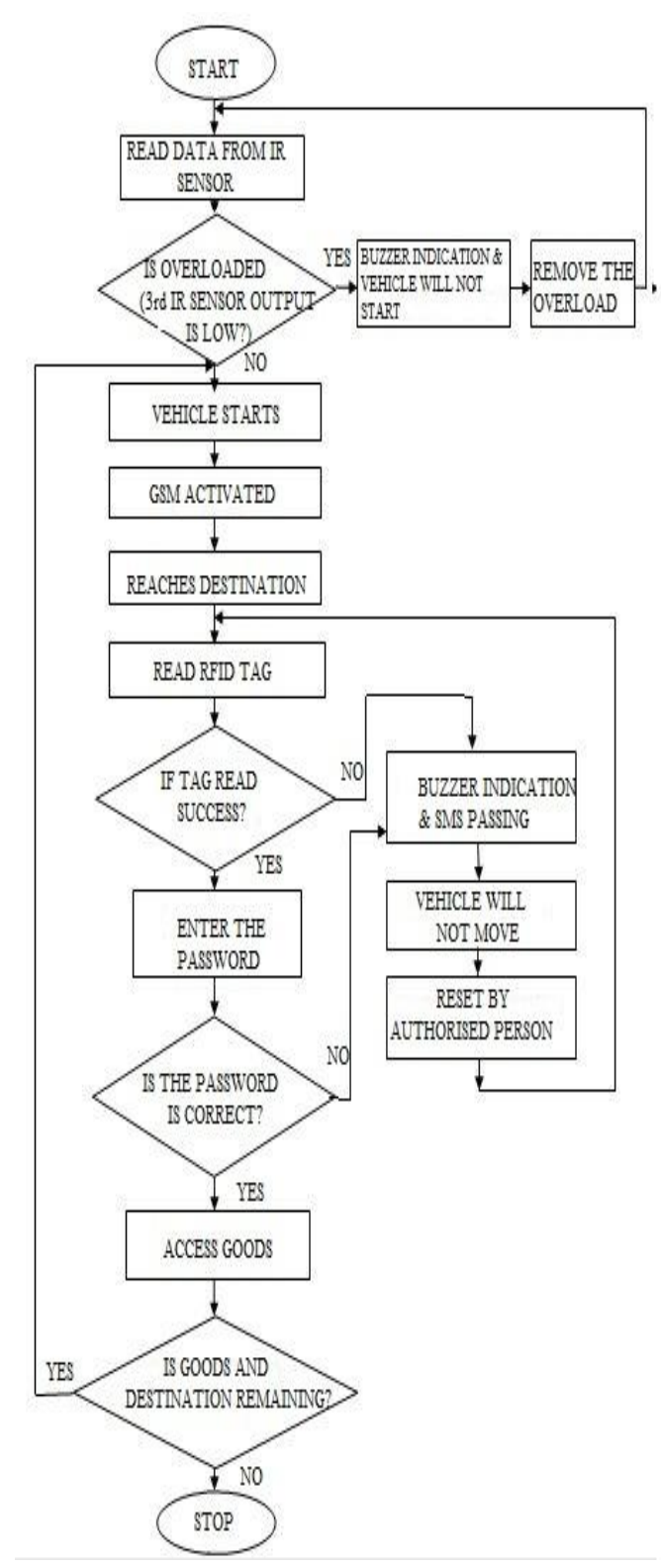

Figure 6.1 Flow chart 
Figure 6.1 shows the workflow of the overall system. This secure system consists of number of processes that has to be performed, which provide the security of the goods. At the first stage goods are loading in to the vehicle. Here we have to make sure that the weight of goods is in the acceptable limit. For this purpose three IR sensors are used to indicate the weight of goods. If the first IR sensor detects the presence of an object, then it will illustrate the loading of first good. Similarly second will inform about the second good and third show the overload condition. If the vehicle is overloaded upon reading the data from the third IR sensor, then a buzzer indication is provided and the overload is removed from the vehicle. Otherwise it will move to the next step. After starting the vehicle it moves to the destination and also GSM get activated. At the destination RFID tag validation will take place. If tag read is success then the system is asking to enter the password otherwise buzzer indication and SMS passing to the source will take place. Then the authorized person will reset the system. If the password is correct system will allow getting access to the goods from the vehicle and again checking whether any good is remaining or not. If remaining then move to the next destination.

\section{Results And Discussions}

Table 7.1 and 7.2 shows the experimental results of the system. Table 7.1 depicts the load results, which explains that if the system is not overloaded the vehicle will start whereas the system becomes overloaded and the indication is obtained from the buzzer and motor will not start. Table 7.2 depicts the tag validation. If the tag is invalid, goods cannot be accessed, if the tag is valid, and the password is correct and goods can be accessed; If the tag is valid and password is incorrect, the goods cannot be accessed.

\section{Experimental results:}

\begin{tabular}{|c|c|c|}
\hline $\begin{array}{c}\text { SL } \\
\text { NO }\end{array}$ & LOADING & RESULTS \\
\hline 1 & $1^{\text {st }}$ load & Motor will start \\
\hline 2 & $2^{\text {nd }}$ load & Motor will start \\
\hline 3 & $3^{\text {rd }}$ load & $\begin{array}{r}\text { Buzzer indication and motor will not } \\
\text { start(over load condition) }\end{array}$ \\
\hline
\end{tabular}

Table 5.1 Loading of goods and the results

\begin{tabular}{|c|c|c|c|}
\hline $\begin{array}{c}\text { SL } \\
\text { NO }\end{array}$ & $\begin{array}{c}\text { TAG } \\
\text { READING }\end{array}$ & PASSWORD & RESULTS \\
\hline 1 & Invalid tag & incorrect & $\begin{array}{c}\text { Buzzer indication \&can't } \\
\text { access goods }\end{array}$ \\
\hline 2 & Valid tag & $\begin{array}{c}\text { Buzzer indication \& can't } \\
\text { access goods }\end{array}$ \\
\hline 3 & Valid tag & correct & Can access the goods \\
\hline
\end{tabular}

Table 5.2 Tag validation and results 


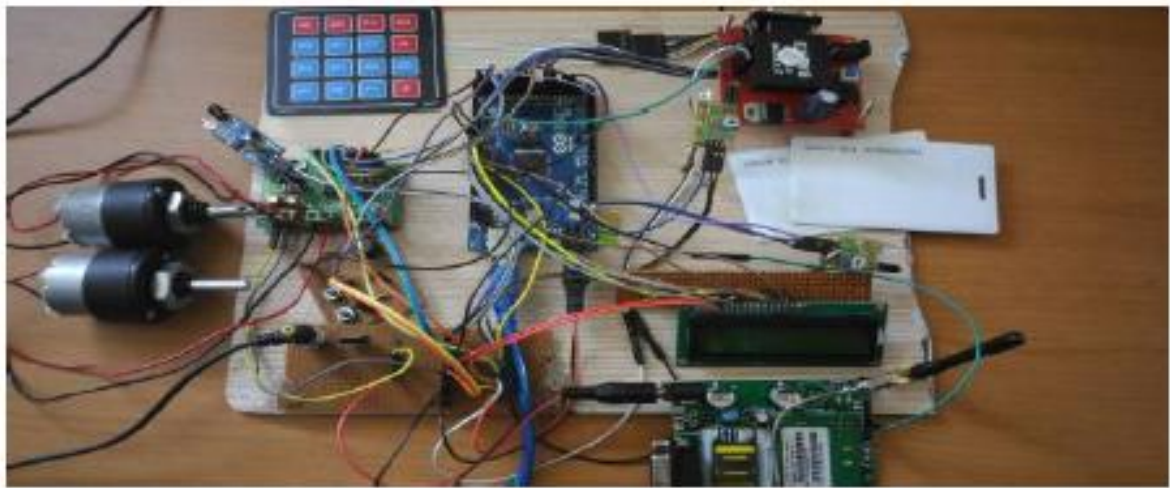

Figure 5.3 Final Prototype

Figure 5.3 shows the final prototype of the system. First the goods to be delivered are loaded in to the vehicle. There is a predefined limit for loading of weights. To sense the weight of goods three IR sensors are arranged horizontally. Vehicle is indicated by a pair of motors. If the weights are within allowable limit, motor gets started which indicate that the vehicle is able to move. Otherwise if there is any overload condition, the motor won't get started. After reaching the destination, the user have to show the RFID tag. If tag validation is successful then the user should enter the password. If the password is correct, the user can access the goods. Otherwise a buzzer indication occurs and a message is send to the source to inform the invalid access. Also there will be a buzzer indication and message passing if an invalid tag is showed.

\section{Conclusion}

This secure logistic management system ensure the safe delivery of goods to respective enterprises. If the goods are accessed by any unauthorized person, the source will be informed about the same. This system will reduce human error by providing RFID validation process. It carries goods to multiple destination at a time which reduces expenses. The system can be applied in industries, medical field and banking. In future the loading and unloading of goods may be automated.

\section{References}

[1]. [1] Sharifkhan Pattan, Sk.Lal John Basha, L. Srinivas Reddy. "Design Of A Hybrid Wireless Terminal System In Chattel TransportationInternational”. Journal of Advanced Technology in Engineering and Science. Volume No.02, Issue No. 12, December 2014

[2]. [2] Ms. Devyani Mahajan and Dr. K. P. Rane, "Literature review on WSN based transport management for courier", International Journal of Scientific \& Engineering Research, Volume 6, Issue 10, October-2015 437 ISSN 2229-5518

[3]. [3] A. Rajasekhar reddy,P.Anwar basha. "The Terminal System Design based on hybrid RFID-GPS in Vehicular communications", International Journal of Modern Engineering Research (IJMER), Vol.2, Issue.4, July-Aug. 2012 pp-2316-2319.

[4]. [4] K.R. Prasanna and M. Hemalatha, "Secure Logistic Management System Using Wireless Technologies", Research Journal of Applied Sciences, Engineering and Technology 4(12): 1785-1789, 2012,ISSN: 2040-7467 